\title{
Questions and answers about the STICH trial: A different perspective
}

Gerald D. Buckberg, MD

From the Department of Cardiothoracic Surgery, UCLA Medical Center, Los Angeles, Calif.

Received for publication Feb 24, 2005; accepted for publication March 1, 2005.

Address for reprints: Gerald D. Buckberg, MD, David Geffen School of Medicine at UCLA, 10833 Le Conte Ave, 62-258 CHS, Los Angeles, CA 90095 (E-mail: gbuckberg@mednet.ucla.edu).

J Thorac Cardiovasc Surg 2005;130:245-9

$0022-5223 / \$ 30.00$

Copyright $\odot 2005$ by The American Association for Thoracic Surgery

doi:10.1016/j.jtcvs.2005.03.029
A recent editorial, the first on this subject, appeared in the Journal $l^{1}$ : "To STICH or not to STICH: We know the answer, but do we understand the question?" Although the article indicates the answer is "to STICH," this report asks whether the STICH investigators' response understood the question.

\section{Patient Selection and Inclusion Criteria}

The underlying principle of the STICH (Surgical Treatment for IschemiC Heart failure) trial involves recognition of the potentially lethal complications of enlarging ventricular volume, and its questions are closely linked to volume measurements, the first entry criteria for inclusion in the trial. This fundamental concept stems from the seminal work of White and colleagues, ${ }^{2}$ showing how increased left ventricular end-systolic volume affects mortality. For example, Figure 1A shows that doubling of mortality follows doubling of volume and defines how death rate worsens after the progressive end-systolic volume expansion. Measuring ventricular volume is a central ingredient of the STICH trial and is expressed as left ventricular end-systolic volume index (LVESVI) in the database. The congestive heart failure (CHF) community must recognize that this vital measurement reflects a major departure from conventional analysis because ejection fraction is now the traditional marker. White and colleagues ${ }^{2}$ have shown, in Figure 1B, the survival discrepancy between conventional ejection fraction and LVESVI measurement. Unfortunately, this central issue is never raised in the invited editorial that just appeared in the Journal.

The normal LVESVI is less than $30 \mathrm{~mL} / \mathrm{m}^{2}$, and STICH trial participants are separated into groups, depending on whether LVESVI is less than $60 \mathrm{~mL} / \mathrm{m}^{2}$ (medical therapy and coronary artery bypass grafting [CABG]) or greater than 60 $\mathrm{mL} / \mathrm{m}^{2}$, where surgical ventricular restoration (SVR) is also tested. Senior, Lahiri, and $\mathrm{Kaul}^{3}$ published a nonrandomized report in which the entry criterion was LVESVI of approximately $60 \mathrm{~mL} / \mathrm{m}^{2}$ and compared medical therapy and CABG. Follow-up data (Figure 2) demonstrated that prognosis was determined on the basis of LVESVI changes over 4 years and was independent of the treatment category. The STICH trial will place randomization into this equation.

A second inclusion criterion is measuring the asynergic (noncontracting region) area: this nonfunctional segment (if it exceeds $>35 \%$ of the left ventricular [LV] perimeter) reflects the ischemic region scar that triggers compensating remote muscle dilation. Another inclusion criterion involves demonstration that the asynergic region is limited to one of the 3 major segments. This concept is based on recognition that revascularization $(\mathrm{CABG})$ of viable remote muscle in nonscarred segments might improve compensatory contractile recovery after the scar is either grafted (in small hearts) or excluded after SVR in larger ventricles. The "remote area concept" reflects an important reason for viability determination of nonscarred regions supplied by the circumflex and right coronary vessels, as was done in the case report.

Consequently, the surgeon and cardiologist must ask 3 different questions than those posed by the authors of this article: (1) How much asynergy (ie, the scar nidus of dilation) exists; (2) is there sufficient compensatory muscle (seen by means of magnetic resonance imaging [MRI], ventriculography, echocardiography, and nuclear medicine studies of remote regions) to resume function; and (3) what is the 


\section{Relative Risk for Death Post MI}

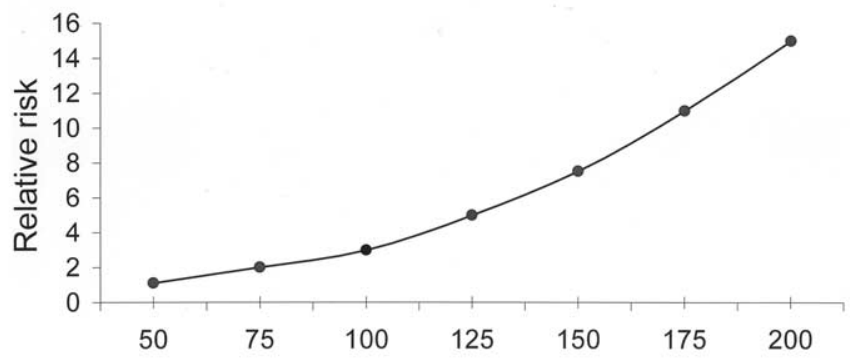

A

End Systolic Volume, $\mathrm{mL}$

White HD. Circulation 1987

\section{LVESV vs. Ejection Fraction}

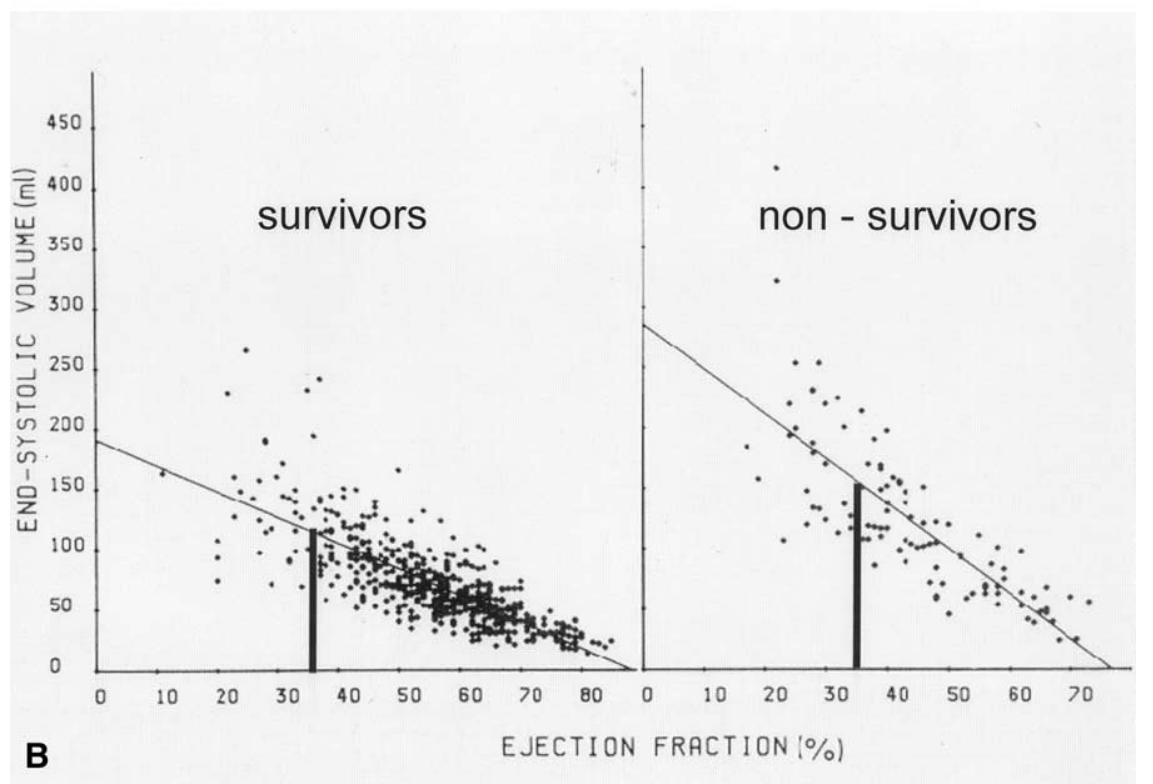

White HD. Circulation 1987
Figure 1. A, Relationship between LV endsystolic volume and mortality. Note that (1) volume is in milliliters, not milliliters per square meter, so that the LVESVI would be twice this number if patient size is $\mathbf{2} \mathbf{m}$ and (2) that volume increase is a surrogate for increased mortality. (Reprinted with permission from White HD, Norris RM, Brown MA, Brandt PW, Whitlock RM, Wild CJ. Left Ventricular EndSystolic Volume as the Major Determinant of Survival After Recovery From Myocardial Infarction. Circulation. 1987;76[1]:4451.) B, Comparison of prognosis in survivors and nonsurvivors in relationship to ejection fraction (solid line is at $35 \%$ ) and LV end-systolic volume in milliliters. Note that lower LV end-systolic volume at $\mathbf{3 5} \%$ ejection fraction is associated with reduced mortality in survivors compared with increased mortality in nonsurvivors when LV end-systolic volume is higher at $35 \%$ ejection fraction. (Reprinted with permission from White HD, Norris RM, Brown MA, Brandt PW, Whitlock RM, Wild CJ. Left Ventricular End-Systolic Volume as the Major Determinant of Survival After Recovery From Myocardial Infarction. Circulation. 1987;76[1]:44-51.) ventricular volume, a measurement obtained by means of MRI, biplane ventriculography, nuclear medicine, and echocardiography?

It seems that a very important task of this prior editorial is to advise the cardiologist or surgeon who wonders how to treat such a patient that the enclosed workup does not provide the STICH team with sufficient information to answer the basic questions that underlie this trial. Failure to address these issues during a response to individuals posing this STICH trial question suggests that the authors do not (1) use these basic criteria in their selection or (2) advise inquiring physicians that correct use of these inclusion criteria is essential to understand this trial.
The STICH protocol uses LVESVI measurement to make decisions about placing patients into the 3 study groups. If volume is less than $60 \mathrm{~mL} / \mathrm{m}^{2}$, the intervention decision relates to comparing the effects of either using medical treatment or adding CABG. Recruitment is down in this 1600-patient cohort because cardiologists are aware that all trials and registries show the benefit of CABG in improving survival in ischemic patients, as summarized in their reported Coronary Artery Surgery Study, and simply do not wish to withhold revascularization in patients with ischemic CHF. More importantly, the editorial does not define limitations of the 3-year observation period, does not emphasize the downward survival trajectory observed with 


\section{Change LVESVI / survival* Initial LVESVI $\sim 60 \mathrm{ml} / \mathrm{m} 2$}

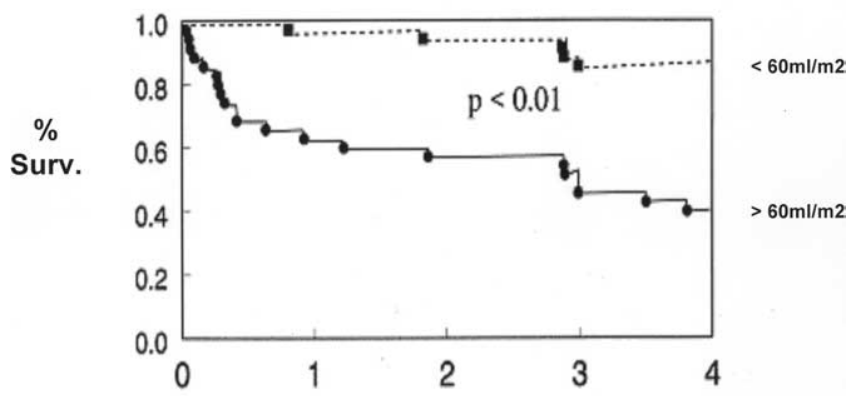

Senior, AJC, 2001

Figure 2. Four-year prognosis of patients treated with either medical therapy or CABG, with an entry criteria of LVESVI approximately $60 \mathrm{~mL} / \mathrm{m}^{2}$. Note the improved prognosis if LVESVI did not change and downward mortality trajectory as LVESVI increased. *Medical or CABG therapy. (Reprinted from The American Journal of Cardiology, vol 88, Senior R, Lahiri A, Kaul S, Effect of Revascularization on Left Ventricular Remodeling in Patients With Heart Failure From Severe Chronic Ischemic Left Ventricular Dysfunction, p 624-9. Copyright (C) 2001, with permission from Excerpta Medica, Inc.)

longer follow-up intervals, ${ }^{4,5}$ and excludes the recent Duke database showing the advantages of $\mathrm{CABG}$ versus medical treatment over a 10-year follow-up interval. ${ }^{6}$ Of interest, this Duke database did not include recurrent $\mathrm{CHF}$ as a late problem $^{7}$ because they only followed death, new myocardial infarction, or repeat $\mathrm{CABG}$ as adverse follow-up events.

If volume is greater than $60 \mathrm{~mL} / \mathrm{m}^{2}$, a frequent finding in patients with $\mathrm{CHF}$, the decision question relates to how SVR fits into the treatment scheme in 1200 patients. A first cohort is divided into 600 patients who do not have either angina or critical coronary lesions and are treated with medical therapy, CABG, or CABG and SVR. The second cohort involves a 600-patient subgroup with angina or critical lesions that will undergo CABG with or without SVR. There is no problem in recruitment in this last group.

\section{Viability and Revascularization}

The issue of viability is somewhat confusing in this editorial because an inclusion criterion for STICH consideration is infarction of the anterior septal region. Consequently, observation of anterior viability in the STICH trial is not as vital in the asynergic scar (the size of which must be measured as $>35 \%$ of $\mathrm{LV}$ perimeter on right anterior oblique ventriculography) as determination of viability of remote muscle that might develop compensatory improvement after revascularization. This remote muscle is viable in

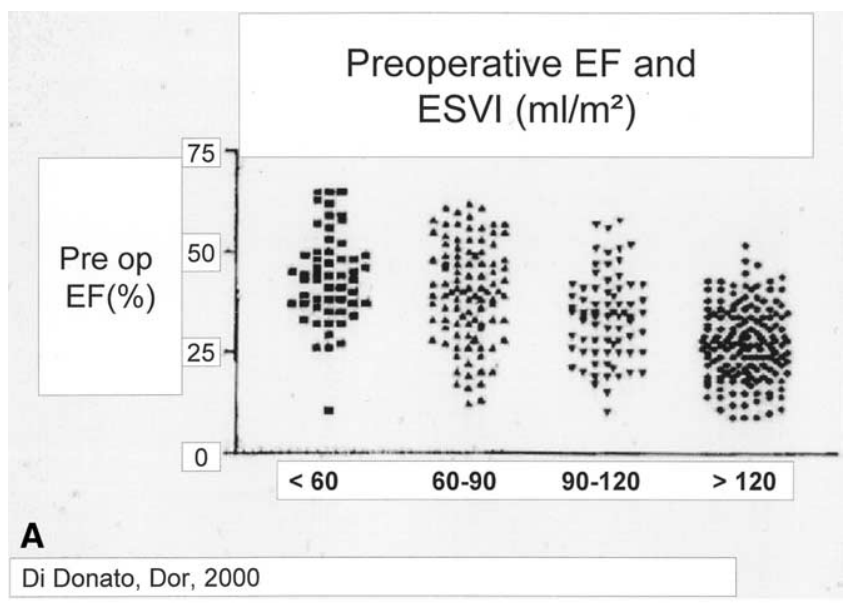

Pre op LVESVI



Figure 3. A, Relationship of ejection fraction (EF) and LVESVI in a cohort of patients with CHF. Note that at an ejection fraction of $35 \%$, LVESVI can range between less than 60 to greater than 120 $\mathrm{mL} / \mathrm{m}^{2}$. (Reprinted from Buckberg GD, Congestive Heart Failure: Treat the Disease, not the Symptom-Return to Normalcy. $J$ Thorac Cardiovasc Surg. 2001;121:628-37.) B, Comparison of 60-month mortality against cumulative survival (hospital deaths excluded) for LVESVI. Note increased mortality as preoperative LVESVI is increased. (From Di Donato M, Toso A, Maioli M, Sabatier M, Stanley AW Jr, Dor V, et al. Intermediate Survival and Predictors of Death After Surgical Ventricular Restoration. Semin Thorac Cardiovasc Surg. 2001;13:468-75. Reprinted with permission of W. B. Saunders Company.)

the patient presented in the editorial. However, the responsibility of the authors is to clarify the trial focus by emphasizing that the surgeon and cardiologist must look at the compensating muscle ${ }^{8}$ rather than the scar, which currently remains the focal area of interest during current viability testing. Addressing remote muscle should be an important component of this editorial because such leadership will 
improve the surgeon's and cardiologist's understanding of the decision tree that underlies the STICH trial.

Additionally, discussions about the importance of viability studies while making decisions about the role of surgical revascularization should overview the recent work of Mahrholdt and associates. ${ }^{9}$ Their findings emphasize the gadolinium aspect of MRI scans (MRI is a part of the STICH trial) by analyzing the amount of damage within the infarct area scar. This is a critical aspect of the evaluation process because most patients show an akinetic rather than a dyskinetic scar. This wall motion finding relates to the consequences of reperfusion by thrombolysis or percutaneous transluminal coronary angioplasty, which salvages the epicardial (and potentially mid myocardial) surface of the infarct region. Early reflow will prevent transmural bulging (dyskinesia) and creates the akinetic area that differs from the aneurysm previously treated by Cooley and coworkers, ${ }^{10}$ when reperfusion strategies were not used. The authors should use this new MRI information to explain why successful revascularization will not allow contractile recovery if more than $50 \%$ of muscle is scarred by gadolinium. ${ }^{9}$ They should also point out that the critical issue is not viability of the scar but rather recognition of why segmental contraction of the scar cannot improve through revascularization of regions containing extensive nonviable muscle. The SVR procedure understands this logic because the operation excludes this nonfunctional region.

\section{Surgical Ventricular Restoration for Ischemic Heart Failure}

The authors present a limited overview of the background role of SVR to treat the dilated heart. Aside from excluding the vital importance of volume measurements, ${ }^{2}$ they should focus on past reports that clarify why bigger ventricular volumes might limit prognosis. ${ }^{11,12}$ Di Donato and cowork$\mathrm{ers}^{8,12}$ reported longitudinal survival studies that demonstrate better survival and functional outcome after SVR interventions when LVESVI is not markedly increased. Athanasuleas and associates ${ }^{13-15}$ found similar late findings, especially in the recent 5-year follow-up of 1198 patients undergoing SVR in the recent RESTORE* team report. The critical role of volume must be clarified because the authors introduce a $\mathrm{CABG}$ article that uses ejection fraction rather than volume measurements to quantify recovery as a contrast to SVR findings of the RESTORE group. ${ }^{16}$

Luciani and coworkers ${ }^{7}$ provided evidence of the prognostic importance of volume rather than ejection fraction, in which a 7-year CABG patient study follow-up identified differences between improved ejection fraction (in his patients) and observed progressive increase of ventricular volume and CHF worsening. These adverse clinical events

*Reconstructive Endoventricular Surgery, returning Torsion Original Radius Elliptical Shape. existed despite improved survival after CABG therapy, and the authors stress the importance of measuring ventricular volume and body oxygen uptake to assess recovery. Furthermore, Di Donato and coworkers ${ }^{12}$ (Figure 3 ) have confirmed the data of White and associates ${ }^{2}$ by showing that volume, rather than ejection fraction, is the vital prognostic component. Yamaguchi and colleagues ${ }^{17}$ have also emphasized the prognostic importance of LVESVI by showing impaired prognosis and increasing incidence of CHF when preoperative LVESVI is greater than $100 \mathrm{~mL} / \mathrm{m}^{2}$. This 1998 observation is now updated ${ }^{17,18}$ by a 2005 report showing that the 54\% mortality that followed successful CABG in a patient population whose preoperative LVESVI value was greater than $100 \mathrm{~mL} / \mathrm{m}^{2}$ was improved to $90 \%$ 5-year survival after restoration (SVR) to produce $\mathrm{LV}$ rebuilding.

\section{Evidence-Based Medicine and Experience}

Evidence-based medicine is the recurrent theme in surveying randomized series. The validity of surgical trials powered to yield creditable results must also address 2 other components: technical proficiency and competent myocardial protection. The importance of adding this credibility concept to surgical trial design was clear from a 1977 Veterans Affairs' randomized CABG study that was done in 597 patients that included 286 surgical and 310 medical patients. ${ }^{19}$ The authors reported $5.6 \%$ surgical mortality, with postoperative deaths ranging from $2 \%$ to $12 \%$, a result that was closely linked to an experience within 12 participating individual centers ${ }^{19}$ that showed similar 36 month outcomes. In 1978, the Cleveland Clinic reported a nonrandomized series of 1000 patients with a mortality of less than $1 \%{ }^{20}$ The overall clinical effect favored experience because obstructed vessels are now treated with revascularization, and current dialogue only relates to creation of the open vessel by using either angioplasty or surgical approaches.

The STICH trial might fall into a similar category because 2800 patients will be studied within the many US and international centers. The editorial states that there is not general acceptance of the SVR procedure that will be performed in only 500 patients among more than 90 participating STICH centers. The potential of approximately 5 patients per center suggests that ensuring competence is essential during evaluation of the role of SVR in high-risk patients with CHF. The recent RESTORE report in 1198 patients (from only 11 contributing centers) might provide some guidelines by reporting $5.3 \%$ operative mortality: $4 \%$ after SVR and CABG and $8.7 \%$ if mitral repair or replacement are added in very large ventricles. This recent RESTORE database might set a benchmark for in-hospital mortality to be expected from STICH centers. Statisticians accurately establish evidence-based medicine, but input for their trial database must involve a safe level of technical competence and satisfactory myocardial protection, so that 
results can avoid inexperience bias that will invalidate any surgical method.

\section{Conclusions}

The questions asked by this current editorial suggest that the editorial of STICH investigators should have advised the cardiologist or surgeon who asks the question "How would you treat this patient?" that the initial workup summary did not have the right measurements. Information on asynergy, remote muscle, and volume are central factors in the STICH evaluation. An important message involves clarifying that the referring physician must know that ejection fraction is a less helpful number than LVESV and suggesting how to obtain this key measurement.

Furthermore, advice about the viability of remote muscle is a new theme and should be emphasized. Additionally, they should define ways that MRI allows study of the underlying scar of the akinetic heart to improve understanding of why its grafting or exclusion might affect prognosis, especially in the 1200 patients with CHF who become SVR candidates. Identifying limitations of 3-year follow-up is needed because medical therapy options are vastly improved. Recognizing this limitation naturally leads to emphasizing the importance of long-term follow-up intervals that are a critical STICH trial component, especially because 10-year data about CABG in the Coronary Artery Surgery Study are discussed. Finally, focus on the role of experience during any randomized surgical series is important to avoid unbiased results. Surgeons act and statisticians count, and both must be done well to define how any randomized or nonrandomized trial can affect future actions.

\section{References}

1. Doenst T, Velazquez EJ, Beyersdorf F, Michler R, Menicanti L, Di Donato M, et al. To STICH or not to STICH: we know the answer, but do we understand the question? J Thorac Cardiovasc Surg. 2005;129: 246-9.

2. White HD, Norris RM, Brown MA, Brandt PW, Whitlock RM, Wild CJ. Left ventricular end-systolic volume as the major determinant of survival after recovery from myocardial infarction. Circulation. 1987; 76:44-51.

3. Senior R, Lahiri A, Kaul S. Effect of revascularization on left ventricular remodeling in patients with heart failure from severe chronic ischemic left ventricular dysfunction. Am J Cardiol. 2001;88:624-9.
4. Trachiotis GD, Weintraub WS, Johnston TS, Jones EL, Guyton RA, Craver JM. Coronary artery bypass grafting in patients with advanced left ventricular dysfunction. Ann Thorac Surg. 1998;66:1632-9.

5. Levy D, Kenchaiah S, Larson MG, Benjamin EJ, Kupka MJ, Ho KK, et al. Long-term trends in the incidence of and survival with heart failure. N Engl J Med. 2002;347:1397-402.

6. O'Connor CM, Velazquez EJ, Gardner LH, Smith PK, Newman MF, Landolfo KP, et al. Comparison of coronary artery bypass grafting versus medical therapy on long-term outcome in patients with ischemic cardiomyopathy (a 25-year experience from the Duke Cardiovascular Disease Databank). Am J Cardiol. 2002;90:101-7.

7. Luciani GB, Montalbano G, Casali G, Mazzucco A. Predicting longterm functional results after myocardial revascularization in ischemic cardiomyopathy. J Thorac Cardiovasc Surg. 2000;120:478-89.

8. Di Donato M, Dor V, Sabatier M, Gensini GF, Toso A, Maioli M, et al. Effects of the Dor procedure on left ventricular dimension and shape and geometric correlates of mitral regurgitation one year after surgery. J Thorac Cardiovasc Surg. 2001;121:91-6.

9. Mahrholdt H, Wagner A, Parker M, Regenfus M, Fieno DS, Bonow $\mathrm{RO}$, et al. Relationship of contractile function to transmural extent of infarction in patients with chronic coronary artery disease. $\mathrm{J} \mathrm{Am} \mathrm{Coll}$ Cardiol. 2003;42:505-12.

10. Cooley DA, Henly WS, Ahmad KH, Chapman DW. Ventricular aneurysm following myocardial infarction: results of surgical treatment. Ann Surg. 1959;150:595-612.

11. Di Donato M, Sabatier M, Dor V, Toso A, Maioli M, Fantini F. Akinetic versus dyskinetic postinfarction scar: relation to surgical outcome in pts submitted to endoventricular circular patch plasty repair. J Am Coll Cardiol. 1997;29:1569-75.

12. Di Donato M, Toso A, Maioli M, Sabatier M, Stanley AW Jr, Dor V, et al. Intermediate survival and predictors of death after surgical ventricular restoration. Semin Thorac Cardiovasc Surg. 2001;13:468-75.

13. Athanasuleas CL, Buckberg GD, Stanley AW, Siler W, Dor V, Di Donato M, et al. Surgical ventricular restoration in the treatment of congestive heart failure due to post-infarction ventricular dilation. J Am Coll Cardiol. 2004;44:1439-45.

14. Athanasuleas CL, Stanley AWH Jr, Buckberg GD, Dor V, DiDonato M, Blackstone EH. Surgical anterior ventricular endocardial restoration (SAVER) in the dilated remodeled ventricle following anterior myocardial infarction. J Am Coll Cardiol. 2001;37:1199-209.

15. Athanasuleas CL, Stanley AW Jr, Buckberg GD, Dor V, Di Donato M, Siler W, et al. Surgical anterior ventricular endocardial restoration (SAVER) for dilated ischemic cardiomyopathy. Semin Thorac Cardiovasc Surg. 2001;13:448-58.

16. Elefteriades J, Edwards R. Coronary bypass in left heart failure. Semin Thorac Cardiovasc Surg. 2002;14:125-32.

17. Yamaguchi A, Ino T, Adachi H, Murata S, Kamio H, Okada M, et al. Left ventricular volume predicts postoperative course in patients with ischemic cardiomyopathy. Ann Thorac Surg. 1998;65:434-8.

18. Yamaguchi A, Adachi H, Kawahito K, Murata S, Ino T. Left ventricular reconstruction benefits patients with dilated ischemic cardiomyopathy. Ann Thorac Surg. 2005;79:456-61.

19. Takaro T, Hultgren HN, Lipton MJ, Detre KM. The VA cooperative randomized study of surgery for coronary arterial occlusive disease II. Subgroup with significant left main lesions. Circulation. 1976; 54(suppl III):III107-17.

20. Sheldon WC, Loop FD, Proudfit WL. A critique of the VA cooperative study. Cleve Clin Q. 1978;45:225-30. 